\title{
Assembleias escolares: uma estratégia para refletir sobre os conflitos interpessoais
}

\author{
Patrícia Souza Ferro Oliveira ${ }^{1}$ \\ Sonia Maria Pereira Vidigal ${ }^{2}$
}

Resumo: Um dos objetivos educacionais é a formação ética do aluno, e, para isso, a escola precisa se preocupar com atividades que proporcionem essa formação. O objetivo deste estudo é apresentar a importância das assembleias escolares para o desenvolvimento moral dos alunos, sendo também uma alternativa para a construção da cidadania e mediação dos conflitos existentes no dia a dia do ambiente escolar. Este trabalho foi desenvolvido por meio de revisão bibliográfica, baseando-se em pesquisas recentes sobre o assunto. O referencial teórico utilizado foi o construtivismo piagetiano. Conclui-se que a assembleia escolar é uma das estratégias de resolução de conflitos coerente com o desenvolvimento da autonomia moral dos alunos. Por ser uma forma prática que contribui para aprimorar as capacidades dialógicas e de valores de não violência, respeito, justiça, democracia e solidariedade, por meio dela é possível que diversos assuntos e situações diárias sejam debatidos no ambiente escolar a fim de auxiliar os alunos a desenvolverem-se moralmente e a adquirir estratégias mais respeitosas de resolução de conflitos, formando cidadãos com atitudes mais democráticas.

Palavras-chave: Assembleias escolares. Moral. Conflito.

\section{School assemblies: a strategy to think about the interpersonal conflicts}

\begin{abstract}
One of the educational goals is the ethical education of students and, therefore, the school has to worry about activities that provide such training. The purpose of this study is to present the importance of school assemblies for the moral development of the students, also it is an alternative to the construction of citizenship and mediation of conflicts in everyday life of the school environment. This academic work was developed by reviewing bibliographies, relating to recent researches about the topic. The theoretical framework used was the Piagetian Constructivism. It was concluded that school assembly is one of consistent conflict resolution strategies with a coherent development of moral autonomy of students. As being a practical way that helps to improve the dialogic skills and values of non-violence, respect, justice, democracy, solidarity, it is possible that several issues and situations of everyday life are discussed in the
\end{abstract}


school environment in order to assist students to develop themselves, acquiring more respectful strategies for solving conflicts and form citizens with democratic attitudes. Keywords: School assemblies. Moral. Conflicts.

\section{Asambleas escolares: una estrategia para reflexionar sobre los conflictos}

Resumen: Uno de los objetivos educacionales es la formación ética del alumno y, para ello, la escuela debe preocuparse con actividades que proporcionen esta formación. El objetivo de este estudio es presentar la importancia de las asambleas escolares para el desarrollo moral de los alumnos, siendo también una alternativa para la construcción de ciudadanía y mediación de conflictos existentes en el día a día del ambiente escolar. El trabajo se desarrolló por medio de revisión bibliográfica, con base en investigaciones recientes sobre el asunto. El referencial teórico utilizado fue el constructivismo piagetiano. Se concluye que la asamblea escolar es una estrategia para la solución de conflictos coherente con el desarrollo de la autonomía moral de los alumnos. Por ser una forma práctica que contribuye para mejorar las capacidades dialógicas y los valores de no violencia, respeto, justicia, democracia, solidaridad, por su intermedio es posible que diversos asuntos y situaciones cotidianas se debatan en el ambiente escolar, para auxiliar a los alumnos en su desarrollo moral y en la adquisición de estrategias más respetosas de solución de conflictos y formación de ciudadanos con actitudes más democráticas. Palabras clave: Asambleas escolares. Moral. Conflictos.

\section{Introdução}

No dia a dia do ambiente escolar, os conflitos são uma constante: agressões verbais e físicas, provocações, vandalismo, ameaças etc. Ao se depararem com eles, muitos professores sentem-se limitados por não saber lidar com tais situações.

Diante dessa realidade, pais, professores e equipe diretiva se questionam sobre as possibilidades de ação que visam diminuir ou extinguir tais atitudes, mesmo sabendo que, ao acabar com tais conflitos, perde-se a oportunidade de trabalhar valores e regras fundamentais para o convívio social.

A falta de tempo do corpo docente e da equipe pedagógica, priorizando a reflexão e o conhecimento do desenvolvimento moral dos alunos, contrapõe-se ao grande enfoque dado, na maior parte do tempo, ao desenvolvimento cognitivo do grupo. Assim sendo, é importante ressaltar o desenvolvimento da questão moral para que o aluno possa perceber que o outro também possui sentimentos, ideias e desejos.

O fato é que se reconhece a necessidade da existência de regras que favoreçam a convivência saudável no ambiente educativo e social, porém, em geral, pouco se reflete ou aborda sobre como a moral se constrói no espaço educacional.

Muitos professores têm como objetivo colaborar para a formação de alunos éticos, autônomos, responsáveis, críticos, capazes de tomar decisões. Contudo, o ambiente sociomoral proporcionado para que seus alunos interajam entre 
si tem características e qualidades com regras diversas. Se esses espaços favorecessem a vivência em um ambiente sociomoral cooperativo, ou seja, aquele que contém características de um ambiente que promove a moral, eles contribuiriam para o desenvolvimento moral dos alunos.

Em grande parte dos casos, observa-se a prática autoritária prevalecer sobre a democrática, pela qual o professor induz seus alunos a elaborar normas que the sejam convenientes do ponto de vista disciplinar, na tentativa de evitar conflitos.

Para entender o que seriam as práticas autoritárias e democráticas, recorre-se a dois autores que explicitam bem os termos:

Na prática autoritária há quebra da liberdade e da licenciosidade, em favor do autoritarismo. A autoridade está relacionada com promover, incentivar, por isso demanda generosidade. Relações justas e generosas geram um clima em que a autoridade do professor e a liberdade do aluno se assumem em sua eticidade (FREIRE, 2000, p. 103).

Visto que as raízes da autonomia moral encontram-se nas relações democráticas, esse ambiente deve propiciar trocas sociais entre pares, oportunidades de crianças assumirem pequenas responsabilidades e de tomar decisões, discutir seus pontos de vista, expressarem livremente seus pensamentos e desejos, investigar e estabelecer relações (VINHA, 1998, p. 43).

Todavia, os conflitos constantes que estão presentes nas escolas e nos ambientes sociais podem receber intervenções que sejam construtivas, favorecendo o desenvolvimento moral do aluno. No entanto, as intervenções podem comprometer esse desenvolvimento. Assim, o que fará a diferença será a atitude do professor ou adulto que estiver mediando o processo de resolução de conflitos.

Nas escolas autocráticas - que promovem a prática autoritária -, os professores, por proporcionarem um ambiente coercitivo ${ }^{3}$, pouco agregam ao desenvolvimento moral dos alunos, podendo até mesmo dificultar esse processo. A postura autoritária não contribui para o desenvolvimento da autonomia na criança, a qual, quando simplesmente obedece a uma regra imposta, está correspondendo à instalação de uma moral heterônoma ${ }^{4}$.

A teoria construtivista compreende os conflitos como uma oportunidade para trabalhar valores e regras, e não apenas como um problema a ser solucionado. O foco não está na resolução do conflito em si, mas no processo, já que o que fará a diferença é a forma pela qual os problemas serão enfrentados. Agindo assim, o professor reconhece a importância de desenvolver nos alunos habilidades que os auxiliem na resolução de conflitos interpessoais, favorecendo a formação de pessoas autônomas.

A prática da elaboração de regras em conjunto com os alunos é um dos recursos efetivos que visa ao desenvolvimento da autonomia moral. O favoreci- 
mento do diálogo é outro instrumento que atua como forma de resolver os conflitos. Porém, o mecanismo mais usual de criação de regras, em uma instituição de ensino, é a imposição destas com o intuito de impedir que problemas diversos persistam em ocorrer.

Para elaborar regras, é necessário compreender em que elas se baseiam, ou seja, os princípios nos quais elas estão pautadas. Esse é o espírito das regras que não indicam como agir, mas sim em nome do que agir. Segundo De La Taille (2000), as regras corresponderiam ao mapa (que indica o caminho claramente), e o princípio, à bússola (que permite a orientação, mas não indica claramente o caminho). Sendo assim, princípios gerais, como justiça, respeito, igualdade e dignidade, servem de parâmetros para a elaboração de regras.

Percebe-se, com certa frequência, que, nas escolas, há muitas regras e poucos princípios, o que leva os alunos a simplesmente obedecer tais normas, mas sem compreendê-las, caracterizando uma educação que reforça a heteronomia. Uma regra, para ser significativa, precisa de um bom argumento para sustentá-la.

Quando é permitida ao aluno a sua participação na elaboração de regras, ele assume o compromisso em cumpri-las por ter refletido e discutido sobre a importância que elas têm, sentindo-se, nesse momento, protagonista do processo que favoreceu o desenvolvimento da cidadania e da moral.

Nessa perspectiva, a escola pode e deve colaborar com a construção da cidadania dos alunos, sendo democrática, inclusiva e de qualidade. Nesse processo, alunos e professores são sujeitos da aprendizagem, interpretando e conferindo sentido aos conteúdos com os quais convivem na escola. A construção de valores democráticos deve ter como alicerce a reflexão e o posicionamento diante dos conflitos diários.

No enfrentamento de situações significativas, complexas e conflitantes do ponto de vista moral, as assembleias escolares se apresentam como um recurso eficaz no trabalho com práticas morais por parte das instituições educativas.

O objetivo deste estudo é apresentar a importância das assembleias escolares na formação moral dos alunos e como alternativa para o desenvolvimento da razão entre o que é certo ou errado diante dos conflitos existentes no dia a dia do ambiente escolar.

A mediação pode ser entendida como uma forma de resolução de questões, na qual as partes, por meio de diálogo, têm a possibilidade, elas próprias, de solucionar seu conflito, contando com a figura do mediador, o qual, nesse caso em especial, é o professor. Por suas características, tal mediação torna-se um meio de solução apropriado a conflitos que abordam relações contínuas, ou seja, relações que são mantidas, apesar do problema vivenciado.

Este artigo foi organizado nas seguintes partes: na primeira, além da contextualização e da sua organização, apresenta-se o problema da pesquisa a ser investigado, os objetivos a serem alcançados, a justificativa e a estrutura do traba- 
lho; a segunda contém a revisão de literatura, descrevendo breves relatos sobre desenvolvimento de regras e limites e sobre a ferramenta "assembleias escolares"; na terceira parte, apresentam-se os resultados e as discussões encontradas em outros estudos; em seguida, para finalizar, destacam-se algumas considerações decorrentes desta investigação.

\section{Formação do desenvolvimento}

Para entender como se dá o desenvolvimento moral de uma pessoa, é necessário compreender que há três tipos de desenvolvimento que estão juntos e são interligados: o desenvolvimento cognitivo, o afetivo e o moral. O desenvolvimento moral depende dos outros dois: do aspecto do desenvolvimento afetivo porque ele mobiliza os recursos do sujeito para determinadas ações e do aspecto cognitivo porque é necessário que esse sujeito consiga se descentrar, perceber diversas perspectivas simultâneas e as relações de causa e efeito decorrentes delas, considerando diversos fatores para que ele possa reconhecer uma dimensão geral, e não somente a sua perspectiva ou a de outra pessoa.

Este estudo se baseia na perspectiva de Piaget, o qual acreditava que os estágios de desenvolvimento cognitivo são processos dinâmicos, e, portanto, a inteligência seria um mecanismo de adaptação do organismo em constante construção de novas estruturas. Essas estruturas se organizam em estágios ou etapas contínuas, com complexidades crescentes, encadeadas umas às outras. Piaget chamou esse fenômeno de "construtivismo sequencial".

Nos estágios de desenvolvimento cognitivo organizados por Piaget, podem-se encontrar: o estágio sensório-motor ( 0 a 2 anos), no qual se desenvolvem os esquemas motores; o pré-operatório ( 2 a 7 anos), fase na qual, além do desenvolvimento dos esquemas motores, a criança também desenvolve os esquemas simbólicos por meio da linguagem e se caracteriza pelo egocentrismo intelectual e social, ocorrendo a incapacidade de se colocar no ponto de vista de outros; o estágio das operações concretas (7 a 11 anos), caracterizado pela capacidade de estabelecer relações e coordenar pontos de vista diferentes, integrando-os de modo lógico e coerente; e, finalmente, o estágio das operações formais (12 anos em diante), no qual a criança, ampliando as capacidades adquiridas na fase anterior, já consegue raciocinar sobre hipóteses e ideias abstratas, tendo a linguagem uma função importantíssima, pois serve de suporte conceitual. Vale destacar que as idades são aproximadas, e não estanques, como alguns estudiosos apontam.

Como se pode perceber, as estruturas dos estágios vão do egocentrismo, quando a criança só percebe si mesma, passando por uma fase concreta, momento em que ela só percebe o visível, e finalmente, até uma fase formal, quando já consegue abstrair conceitos e ideias. É somente na última fase que ela consegue desenvolver, de forma mais aprofundada, as relações que envolvem o desenvolvimento moral. 


\section{Implicações pedagógicas das regras e limites}

$\mathrm{Na}$ maioria dos espaços educacionais, percebe-se que pouco ou nada se discute sobre o desenvolvimento moral dos alunos. Os cursos de formação de professores priorizam discussões sobre o desenvolvimento e a aprendizagem do aluno como um todo.

Ramos, Wrege e Vicentin (2012) afirmam que, na autonomia, a pessoa não se submete a uma norma simplesmente pela obediência à autoridade, mas sim porque compreende e aceita tais normas e limites. O estabelecimento de limites é um dos assuntos discutidos entre os profissionais da área da educação e do desenvolvimento infantil e pelos pais, pois favorece a construção da autodisciplina e leva ao entendimento sobre a autoridade.

As crianças podem buscar a autonomia, mas, ainda assim, são muito dependentes do adulto para efetivá-la. Antes de conseguirem ter a liberdade para realizar seus desejos, escolher suas tarefas e tomar suas próprias decisões perante o grupo, elas necessitam da orientação e não de uma autoridade autoritária do adulto. Elas precisam de apoio, de opções, de realizar escolhas e de experimentar uma autonomia própria (VIEIRA, 2009, p. 2).

Quando De La Taille (2000, p. 76) descreve as normas e o entendimento delas, ele destaca que "o importante é que o sujeito passa a legitimar (aceitação interna) as normas morais". O indivíduo as aceita devido a um respeito unilateral ${ }^{5}$ ou também por imposição ou por uma autoridade, favorecendo a heteronomia, ou seja, pela obediência às pessoas com poder, como os seus pais e professores.

Para Ramos, Wrege e Vicentin (2012, p. 64) "as normas são formuladas a partir de princípios, e estes não se referem a como agir, mas sim em nome do que agir". Quando as regras são elaboradas em conjunto com os alunos, por meio de rodas de conversas ou de assembleias escolares, esse procedimento auxilia o desenvolvimento da autonomia moral e o favorecimento do diálogo como forma de resolver os conflitos. Esse processo ainda auxilia o aluno a desejar a norma porque julga que é o melhor, mesmo, muitas vezes, indo contra um desejo individual, pois nem sempre é agradável respeitá-la. $\mathrm{O}$ aluno que é obediente apenas por medo das regras acordadas pela escola acaba por desobedecê-las. Então se percebe que o que parecia uma aceitação das normas era somente medo de uma provável punição concreta ou afetiva (MENIN, 1996).

Assim sendo, a criança pode simplesmente seguir normas com o intuito de agradar por medo de perder a amizade ou ser punida, reações essas que atrapalham a compreensão das razões das regras, podendo, em longo prazo, apresentar consequências indesejadas, visto que a criança pode não construir suas próprias razões para seguir regras morais (VIDIGAL; VICENTIN, 2012). 
As normas passam a ter muito mais valor quando o educador consegue mostrar ao aluno que o cumprimento delas pode trazer o bem-estar e a satisfação pessoal quando respeitadas. Além disso, é importante que se mostre e se faça refletir sobre as consequências naturais do não cumprimento dessas normas - por exemplo, quando um colega de classe se recusa a emprestar um material escolar a outro colega porque este tem o hábito de danificar propositalmente as coisas alheias. Assim, o aluno vai, aos poucos, percebendo a necessidade das regras que gerenciam as relações entre as pessoas (FERREIRA, 2009).

Assim, as regras devem surgir da necessidade, ou seja, a partir de uma situação ou de um problema que aparece naturalmente, que incomoda e exige uma solução.

Segundo Tognetta e Vinha (2003, p. 56), existem dois tipos de regras: as negociáveis, que são os chamados combinados (não correr dentro da sala de aula, por exemplo); e outras que não são negociadas, como é o caso de não agredir.

Os princípios como a justiça, o respeito (a si mesmo, ao outro e ao patrimônio), a igualdade e a dignidade são explicadas, mas sua validade ou pertinência não são passíveis de discussão. Não se debate se é bom ser justo, ou se deve ou não tratar o outro com respeito, como se esses princípios fossem uma simples questão de ponto de vista, de opinião pessoal. O que se discute é "como se faz justiça?", "o que significa tratar o outro com respeito?”. A escola deve possuir princípios gerais (não negociáveis) que servirão de parâmetros para a elaboração das regras (VINHA, 2003, p. 254).

Logo, para alcançar um excelente trabalho com a construção de normas na escola, é importante que o educador conheça a evolução da prática e da consciência das regras, além de buscar entender como as crianças a percebem e porque, na maioria das vezes, não conseguem cumpri-las.

As relações de respeito unilateral e de coação, que se estabelecem espontaneamente entre o adulto e a criança, contribuem para a constituição de um primeiro tipo de controle lógico e moral [...]. Do ponto de vista intelectual, o respeito que a criança tem pelo adulto tem por efeito provocar o aparecimento de uma concepção anunciadora da noção de verdade: o pensamento deixa de afirmar simplesmente o que lhe agrada para se conformar com a opinião do ambiente (PIAGET, 1994, p. 298).

Para De La Taille (2000, p. 101), "não se faz uma pergunta cuja resposta já está de antemão definida e inegociável”. Em outras palavras, existem regras que não são negociáveis já inseridas desde o começo do ano, no dia a dia dos alunos, para que possam habituar-se. Só assim, em um processo constante, os alunos vão acrescentando outras regras ao sentirem necessidade - as negociáveis - ou até mesmo mudando as já existentes elaboradas em momentos anteriores. 
Para que as regras sejam cumpridas em sala de aula, é importante que os professores possam associá-las ao bem-estar, à satisfação pessoal no dia a dia dos alunos, de maneira que possam respeitá-las e também refletir sobre as consequências naturais do não cumprimento delas. Uma das maneiras de se colocar em prática a legitimação das normas de maneira democrática é por meio de assembleias escolares.

\section{Assembleias escolares}

A escola deve se preocupar com a construção da cidadania, com o desenvolvimento moral dos alunos e com a preservação da integridade de todos os membros da comunidade escolar. Para isso, ela deve ser democrática, inclusiva e de qualidade. A escola deve promover, na teoria e na prática, as condições mínimas para que tais objetivos sejam alcançados.

Pensando na cidadania, para que a escola alcance um ambiente sociomoral cooperativo, é importante que haja justiça, pois só dessa forma haverá a liberdade individual e coletiva.

Assim sendo, a educação para a cidadania deve objetivar o desenvolvimento de competências para lidar com a diversidade e com os conflitos de ideias, com as influências da cultura e com os sentimentos e as emoções presentes nas relações do sujeito consigo mesmo e com o mundo.

A educação para a cidadania e para a vida em uma sociedade democrática demanda a construção de personalidades morais, de cidadãos autônomos que buscam a felicidade e o bem-estar pessoal e coletivo. Para atingir tais objetivos, usam-se propostas educativas fundamentadas na resolução de conflitos e problemas cotidianos, e uma dessas propostas que contempla esse objetivo são as assembleias escolares.

As assembleias escolares são uma forma prática para o desenvolvimento das capacidades dialógicas e de valores que favoreçam o respeito mútuo. Para Ramos, Wrege e Vicentin (2012), as assembleias escolares destinam-se a um momento escolar organizado para que os membros da escola possam falar, com o objetivo de melhorar a convivência e o trabalho escolar.

As assembleias podem ser caracterizadas como um momento em que se permite que os membros escolares possam expor suas ideias para melhorar o ambiente escolar (PUIG, 2000). E também para que o aluno desenvolva maneiras mais éticas de lidar com os conflitos interpessoais.

É um momento oportuno para os alunos pensarem em conjunto sobre a ocorrência de situações próprias do ambiente escolar, analisando-as para resolver problemas, sugerir ideias ou ainda refletir sobre uma condição inegociável.

Além da importância em solucionar problemas do dia a dia, as assembleias também ajudam os alunos a refletir sobre seus atos no ambiente escolar: 
A assembleia é um espaço para pensar no porquê de uma regra e no princípio que a sustenta. De fato, a assembleia permite que os alunos participem em muitas situações na tomada de decisões da escola e se sintam pertencentes a esse universo (RAMOS; WREGE; VICENTIN, 2012, p. 72).

Puig (2000) propõe quatro tipos de assembleias escolares: as assembleias de classe, a escolar, a docente e o fórum escolar.

As assembleias de classe podem ser realizadas com alunos a partir do $2^{\circ}$ ano do Ensino Fundamental. Nelas são discutidas situações do dia a dia escolar e propõe-se que sejam realizadas semanalmente. A partir do $6^{\circ}$ ano, essas assembleias já podem ser realizadas quinzenalmente e coordenadas por um dos professores da classe ou pelo orientador da série.

A assembleia escolar é mais abrangente, pois envolve as classes de cada turma para discutir a organização ou projetos. Propõe-se que sejam realizadas mensalmente, contando com a participação de todos os professores, dois alunos representantes de cada sala, coordenadoras, orientador e representante dos funcionários.

A assembleia docente tem como propósito discutir a relação entre os professores e a direção, bem como o projeto político-pedagógico e conteúdos administrativos. É esperada a participação de todos os professores e a direção representante da secretaria de educação. Propõe-se que ocorra mensal ou bimestralmente.

No fórum escolar, prioriza-se valorizar a relação escola-comunidade. A proposta é que a escola organize reuniões semestrais convidando todos os atores da comunidade e suas famílias para que se envolvam de forma sistematizada no projeto pedagógico da escola, gerando sugestões para os temas que pautarão os projetos da escola durante o semestre seguinte.

Para Araújo (2015), as diferentes formas de assembleias permitem a construção de uma realidade educativa. Ramos, Wrege e Vicentin (2012) afirmam que a importância de exercer papéis sociais distintos daqueles que se estão acostumados ajuda na descentralização pessoal e desenvolve aspectos cognitivos importantes para os processos de construção da autonomia moral, favorecendo o aspecto crítico nas relações interpessoais.

Pode-se perceber que as assembleias são uma forma de participação democrática, na qual todos têm voz e vez, com intuito de gerar reflexões sobre os acontecimentos diários no ambiente escolar.

Essa é a maneira de buscar a igualdade trabalhando os conflitos, articulando os princípios de igualdade e equidade na convivência em comum, ou seja, por meio das assembleias, é possível dialogar, garantindo que todos possam participar com direito de exprimir suas opiniões (ARAÚJO, 2015).

O processo de implantação das assembleias depende da preparação dos envolvidos e da sua expectativa. Além disso, depende do engajamento de todos 
para que tudo ocorra como o esperado. A escolha do local, dos alunos, dos coordenadores, a pauta, a organização da ata de avaliação (RAMOS; WREGE; VICENTIN, 2012) também são elementos importantes que devem ser observados com atenção.

Deve-se ter um cuidado na sua preparação, por exemplo, na discussão e criação de normas, ou seja, deve-se levar em consideração o bem-estar de uma maioria, sem que ninguém seja desrespeitado por essa regra, isto é, a maioria não pode usufruir de algo à custa de alguém.

Vale ressaltar que, conforme Tognetta e Vinha (2007, p. 100) apontam, as assembleias não são mágicas ou panaceia que resolvem todos os problemas, mas sim um instrumento que auxilia os alunos a se conscientizarem dos seus atos e a pensar sobre suas ações, de maneira que os problemas da escola não sejam apenas coibidos.

As assembleias possibilitam que os professores conheçam seus alunos e coloquem em prática a democracia e o respeito mútuo para o bem-estar de todos. E por isso fica claro que as assembleias escolares devem ser um processo democrático, construindo as questões psicológicas de cada integrante envolvido.

\section{Procedimento para a realização das assembleias}

Embora cada assembleia tenha sua peculiaridade, alguns procedimentos são realizados em comum a todas. Uma primeira questão a se considerar é a mobilização do grupo. O professor deve mostrar a importância do debate e da participação de todos em uma assembleia. Araújo (2015, p. 46) ressalta que, para introduzir uma assembleia em uma classe, deve-se propor uma atividade didática que leve os alunos a discutir a importância do diálogo, na qual haverá a possibilidade da apresentação de situações escolares cotidianas, visando ao encaminhamento de propostas que melhorem o convívio de classe.

Espera-se, portanto, que, nas assembleias, haja diálogo e participação de todos com o objetivo de resolver os conflitos e tornar a convivência mais positiva e democrática.

O conflito é algo inerente à vida e não deve ser encarado como algo a ser eliminado ou escondido. O desafio a ser encarado nos espaços públicos é saber lidar com as diferenças e aproveitá-las como matéria-prima para o desenvolvimento pessoal e coletivo (ARAÚJO, 2015, p. 47).

Outra questão também importante é a periodicidade das assembleias. Ela deve ter um espaço garantido e, desse modo, o excesso de trabalho, a falta de tempo ou as avaliações pessoais não devem ser usadas como argumentos para adiar a ocorrência nos dias preestabelecidos (ARAÚJO, 2015). 
A convicção de que as assembleias ocorrerão no dia previsto, e com a periodicidade combinada, garante que os membros que delas participam possam se organizar e construir maneiras de atuação que se mantenha ao longo do tempo (ARAÚJO, 2015, p. 45).

Como foi visto, a periodicidade ideal da assembleia escolar é: semanalmente para as assembleias de classe; mensalmente para a escolar; mensal ou bimestralmente para a docente; e semestralmente para o fórum escolar.

A pauta de uma assembleia é iniciada antecipadamente ao momento da sua ocorrência, ou seja, assim que terminada, logo se inicia a preparação da próxima assembleia. Para sua preparação, em primeiro lugar, é estipulado o tema que será discutido, podendo ser uma crítica ou felicitação conforme registros prévios feitos pelos participantes em uma cartolina afixada em mural ao qual todos os envolvidos tenham acesso. O processo de organização da pauta deve levar em consideração o estabelecimento de uma hierarquia dos temas, agrupando-se temas parecidos e garantindo que todos os assuntos estejam presentes na pauta já previamente definida.

As assembleias, como já foram discutidas anteriormente, possibilitam a discussão democrática e envolvem assuntos do convívio escolar que afetam o coletivo da classe ou da escola.

"A escola, portanto, é uma instituição social permeada e, por isso, não pode ser tratada como igual no exercício de sua obrigação" (ARAÚJO, 2015, p. 52). Dessa maneira, as assembleias devem ser um momento de diálogo que permita a construção dos valores socialmente desejados, ou seja, discutem-se o convívio escolar, as relações interpessoais e os problemas que afetam cada sala.

De modo geral, as assembleias auxiliam os participantes quanto ao entendimento dos limites sociais, ao respeito e ao cumprimento dos objetivos na vida social e política da sociedade.

\section{Considerações finais}

Sabe-se que os conflitos interpessoais ocorrem com frequência em todos os ambientes onde há convivência humana. A forma de encarar o conflito interfere na maneira como as pessoas lidam com ele. Tais conflitos podem ser construtivos ou destrutivos. São as atitudes do adulto no processo de resolução que farão a diferença. Trabalhar com o conflito, de forma que os alunos aprendam melhores formas de se relacionarem, é uma das tarefas da escola.

Há dois tipos de intervenções que auxiliam os alunos a pensar sobre seus conflitos, a analisar as consequências de seus atos e a buscar formas mais respeitosas de relacionarem-se: as diretas e as indiretas. As intervenções diretas são as mediações que auxiliam os envolvidos a resolver o fato ocorrido, enquanto as indiretas são atividades que contribuem para a apropriação racional de valores éticos e democráticos, sendo as assembleias escolares uma das possibilidades de intervenção indireta. 
Nos ambientes educativos em que se realizam as assembleias escolares, os alunos têm oportunidades de expor seus pensamentos, fazer críticas, propor novas possibilidades, participando, assim, da sua formação ética e moral por meio do favorecimento de momentos de reflexão individual e coletiva.

A teoria construtivista compreende os conflitos como oportunidades de aprendizagem, e não como problemas a serem resolvidos ou situações a serem evitadas. Assim, sabendo que existem instrumentos capazes de colaborar com o processo da formação moral dos alunos, pode-se considerar que as assembleias escolares se apresentam como um deles, pois proporcionam aos alunos a oportunidade de repensar seus atos e elaborar ações mais justas e reflexivas para a resolução dos problemas.

Recebido: 28/08/2017

Revisado pelo autor: 26/09/2017 Aceito para publicação: 24/10/2017

\title{
Notas
}

1 Pós-Graduação em Psicopedagogia pela Universidade Metodista de São Paulo (2016). Graduação em Pedagogia pela Universidade do Vale do Paraíba (1998). Atualmente, é professora do $4^{\circ}$ ano do Ensino fundamental I do Instituto São José, em São José dos Campos/SP. E-mail: psouzaferro@yahoo.com

2 Doutorado pela Faculdade de Educação da Universidade de São Paulo (USP) (2016). Mestrado pela Faculdade de Educação da USP (2011), com estágio sanduíche na Universidade de Harvard. Especialização em Relações Interpessoais pela Universidade de Franca (UNIFRAN) (2007). Graduação em Pedagogia (licenciatura) pela USP (1989) Professora convidada no curso de Psicopedagogia da Universidade Metodista de São Paulo. E-mail: smpvidi@gmail.com

$3 \mathrm{O}$ ambiente coercitivo é aquele marcado pela relação punitiva entre as partes.

4 A moral heterônoma descreve um período em que o aluno obedece e está submisso a regras morais imposta pelos adultos (DUQUE, 2006).

$5 \mathrm{O}$ respeito unilateral é a primeira forma de respeito que aparece no desenvolvimento do ser humano. Esse sentimento constitui-se nas relações de coação social, cujo protótipo é a relação estabelecida entre a criança e seus pais ou com outros adultos significativos para ela. A obediência tem origem nesse tipo de relação. A criança atribui um valor absoluto às normas, opiniões e valores desses adultos. Ela imita os exemplos que eles lhe dão e adota a sua escala de valores (FREITAS, 2002, p. 305-306).

\section{Referências}

\author{
ARAÚJO, Ulisses. Autogestão na sala de aula: as assembleias escolares. São \\ Paulo: Summus, 2015. \\ DE LA TAILLE, Yves. Limites: três dimensões educacionais. São Paulo: \\ Ática, 2000.
}


DUQUE, Celeste. Desenvolvimento moral: perspectiva de Kohlberg. Ebah, 14 abr. 2006.

FERREIRA, Benisia Grosser. A construção dos limites das crianças na educação infantil. 2009. Monografia (Trabalho de Conclusão de Curso de Pedagogia) - Universidade Federal do Rio Grande do Sul, Porto Alegre, 2009.

FREIRE, Paulo. Pedagogia da indignação: cartas pedagógicas e outros escritos. São Paulo: UNESP, 2000.

FREITAS, Lia Beatriz. Piaget e a consciência moral: um kantismo evolutivo? Psicologia: Reflexão e Crítica, v. 15, n. 2, p. 303-308, 2002.

MENIN, Maria. Desenvolvimento moral: refletindo com pais e professores. In: MACEDO, Lino de (Org.). Cinco estudos de educação moral. São Paulo: Casa do Psicólogo, 1996.

PIAGET, Jean. Biologia e conhecimento. 2. ed. Vozes: Petrópolis, 1994.

PUIG, Joseph. Democracia e participação escolar: propostas de atividades. São Paulo: Moderna, 2000.

RAMOS, Adriana de Melo; WREGE, Mariana Guimarães; VICENTIN, Vanessa. A organização das regras e assembleias em sala de aula: obedecer à autoridade ou aos princípios? In: TOGNETTA, Luciene Regina; VINHA, Telma Pileggi (Orgs.). É possível superar a violência na escola? Construindo caminhos pela formação moral. São Paulo: Editora do Brasil, 2012. p. 60-77.

TOGNETTA, Luciene Regina; VINHA, Telma Pileggi. Quando a escola é democrática: um olhar sobre a prática das regras e assembleias na escola. Campinas: Mercado de Letras, 2007.

VIDIGAL, Sonia Maria; VICENTIN, Vanessa. Processo de resolução de conflito entre crianças e adolescentes. In: TOGNETTA, Luciene Regina; VINHA, Telma Pileggi (Orgs.). É possível superar a violência na escola? Construindo caminhos pela formação moral. São Paulo: Editora do Brasil, 2012. p. 78-97.

VIEIRA, Analúcia de Morais. Autoridade e autonomia: uma relação entre a criança e a família no contexto infantil. Revista Iberoamericana de Educación, n. 49/5, p. 1-10, maio 2009.

VINHA, Telma Pileggi. Reflexões sobre a teoria de piaget e a construção da autonomia moral. Dois Pontos: Teoria e Prática em Educação, v. 38, n. 4, p. 43-46, ago./out. 1998. 